\title{
Treatment-related gonadotoxicity in young male cancer survivors: a comparative cross-sectional study
}

\author{
Maryna Krawczuk-Rybak', Marcin Plonowski', Beata Zelazowska-Rutkowska², \\ Malgorzata Wojtkowska², Bogdan Cylwik², Jolanta Skalska-Sadowska ${ }^{3}$, Jacek Wachowiak ${ }^{3}$, \\ Dorota Sega-Pondel ${ }^{4}$, Bernadeta Kazanowska ${ }^{4}$, Teresa Stachowicz-Stencel ${ }^{5}$, \\ Joanna Stefanowicz ${ }^{5}$, Iwona Malinowska ${ }^{6}$, Michal Matysiak ${ }^{6}$, Andrzej Koltan ${ }^{7}$, Mariusz Wysocki ${ }^{7}$, \\ Aneta Pobudejska-Pieniazek ${ }^{8}$, Tomasz Szczepanski ${ }^{8}$, Borys Przybyszewski ${ }^{9}$, Wanda Badowska ${ }^{9}$, \\ Aneta Czajnska-Deptula ${ }^{10}$, Bozenna Dembowska-Baginska ${ }^{10}$, Dorota Slawinska ${ }^{11}$, \\ Jerzy Kowalczyk ${ }^{11}$, Elzbieta Kamienska ${ }^{12}$, Tomasz Urasinski'2, Anna Wawrzenczyk ${ }^{13}$
}

\footnotetext{
'Department of Paediatric Oncology and Haematology, Medical University of Bialystok, Bialystok, Poland 2Department of Paediatric Laboratory Diagnostics, Medical University of Bialystok, Poland

${ }^{3}$ Department of Paediatric Haematology, Oncology, and Haematopoietic Stem Cell Transplantation, Institute of Paediatrics, University of Medical Sciences, Poznan, Poland

${ }^{4}$ Department and Clinic of Paediatric Oncology, Haematology, and Bone Marrow Transplantation, Wroclaw Medical University, Wroclaw, Poland

${ }^{5}$ Department of Paediatrics, Haematology, and Oncology, Medical University of Gdansk, Gdansk, Poland ${ }^{6}$ Department of Paediatric Haematology and Oncology, Medical University of Warsaw, Warsaw, Poland

${ }^{7}$ Department of Paediatric Haematology and Oncology, Collegium Medicum, Nicolaus Copernicus University, Bydgoszcz, Poland

${ }^{8}$ Department of Paediatric Haematology and Oncology, Medical University of Silesia, Zabrze, Poland

${ }^{9} \mathrm{Haematology}$ and Oncology Department at the Children State Hospital, Olsztyn, Poland

${ }^{10}$ Department of Paediatric Oncology, The Children's Memorial Heath Institute, Warsaw, Poland

${ }^{11}$ Department of Paediatric Haematology and Oncology, Medical University, Lublin, Poland

${ }^{12}$ Department of Paediatrics, Haematology, and Oncology, Pomeranian Medical University, Szczecin, Poland

${ }^{13}$ Department of Paediatric Oncology and Haematology, W. Buszkowski Children's Hospital, Kielce, Poland
}

\section{ABSTRACT}

Introduction: Male gonads are susceptible to the deleterious effect of anticancer therapy (chemotherapy, radiation to the pelvis, central nervous system, or total body irradiation). Hormonal dysfunction after anticancer treatment was evaluated in young male cancer survivors.

Material and methods: In 153 male adolescent cancer survivors divided into three risk groups (low-LR, moderate-MR, and high-HR) and 24 controls, gonadal and pituitary hormones were analysed. FSH, LH, and testosterone levels were assessed in all the studied patients using immunoenzymatic techniques, dimeric inhibin B - by ELISA method.

Results: All cancer survivor groups had lower mean values of inhibin B $(86.87 \pm 69.07 \mathrm{ng} / \mathrm{l} \mathrm{vs.} 161.07 \pm 60.64 \mathrm{ng} /$; $p<0.001)$, and higher FSH $(10.23 \pm 13.35 \mathrm{mIU} / \mathrm{l}$ vs. $4.38 \pm 2.39 \mathrm{mIU} / \mathrm{l} ; p<0.001)$ and $\mathrm{LH}(5.0 \pm 3.43 \mathrm{IU} / \mathrm{l}$ vs. $3.58 \pm 2.17 \mathrm{IU} / \mathrm{l} ; p=0.016$ ); testosterone levels were comparable to the controls. Abnormal values of inhibin B were found: in $15.2 \%$ of survivors in LR, $47.6 \%$ in MR, and $94.1 \%$ - in the HR group. Elevated FSH levels were seen in $20.4 \%$ of survivors in LR, $47.4 \%$ in MR, and $92.2 \%$ in the HR group. The inhibin B: FSH ratio

\section{ADDRESS FOR CORRESPONDENCE:}

Maryna Krawczuk-Rybak, MD, PhD, Prof., Department of Paediatric Oncology and Haematology, Medical University of Bialystok, Waszyngtona 17, 15-274 Bialystok, phone/fax: +48 8574508 46, e-mail: rybak@umb.edu.pl 
was lowered in MR and HR risk groups. We did not observe any influence of the age at treatment and the time since treatment termination on the analysed hormonal values.

Conclusions: Anticancer treatment increases the risk of gonadal damage, particularly in the HR group. Patients and parents ought to be informed about the risk of lowered reproductive function, and pretreatment semen cryopreservation should be recommended.

\section{KEY WORDS:}

childhood cancer survivors, late effect, fertility, gonadal function, inhibin B.

\section{INTRODUCTION}

Currently more than $80 \%$ of patients treated for cancer during childhood achieve long-term survival. However, more than $60 \%$ present at least one late effect of the treatment. Some of them are serious and result in higher mortality (cardiac or lung dysfunction, second cancers), whereas others are the cause of augmented morbidity, organ dysfunction, and lower quality of life [1-3]. Endocrine disturbances are the most frequent complications after anticancer treatment affecting nearly half of childhood cancer survivors. Dysfunction of the hypothalamic pituitary axis, thyroid disorders, abnormal growth and pubertal development, glucose metabolism, as well as gonadal dysfunction can be observed [2,3]. Male gonads are more susceptible to the deleterious effect of anticancer treatment than female ones. The gonadal function can be affected by the type of chemotherapy, administration of higher doses of gonadotoxic cytostatics such as alkylating agents, radiation to the pelvic area, and total body irradiation, leading to oligospermia and deleterious changes in sperm quality $[4,5]$. Anticancer protocols include some cytostatics that exert various effects on the gonads [6-8]. Wallace et al. divided all the most frequent paediatric cancers into three groups according to their gonadotoxicity [9]. Treatment protocols for acute lymphoblastic leukaemia (ALL), Wilms' tumour, soft tissue sarcoma, germ-cell tumour, retinoblastoma brain tumour after surgery, and cranial irradiation $<24$ Gy were classed into a low-risk group (LR); for acute myeloblastic leukaemia (AML), hepatoblastoma, osteosarcoma, non-metastatic Ewing's sarcoma, neuroblastoma (NBL), non-Hodgkin's lymphoma (NHL), and brain tumour after irradiation $>24$ Gy were classed into a medium-risk group (MR); and the patients after total body irradiation (TBI), radiotherapy of the areas located in the pelvis or testes, megachemotherapy before bone marrow transplantation (BMT), Hodgkin's lymphoma treated with alkylating agents, stage IV of soft tissue sarcoma (STS), or Ewing's sarcoma were referred to a high-risk group (HR). The probability of infertility in the low-risk group was less than $20 \%$, in the medium-risk group it was between $20 \%$ and $80 \%$, and in the high-risk group it was above $80 \%$ [9].

Semen analysis is the gold standard for determining male fertility. Inhibin B, a glycoprotein hormone and the product of Sertoli cells, plays an important role in the regulation of the hypothalamic-pituitary-gonadal action.
In younger prepubertal boys or when sperm analysis is impossible to make (e.g. lack of patient consent), inhibin $B$ is used as an indirect marker of spermatogenesis [10]. In our previous study, we analysed male gonadal function in small groups [11], whereas in the current study the hormonal status was assessed in a large group of adolescents and young adults, cancer survivors, from Polish Departments of Paediatric Oncology.

\section{MATERIAL AND METHODS}

We included 153 adolescents and young men who visited the outpatient clinics belonging to the Departments of Paediatric Oncology and Haematology of the Medical Universities of: Bialystok, Poznan, Wroclaw, Gdansk, Warszawa, Bydgoszcz, Zabrze, Olsztyn, Lublin, and Szczecin, and the Children's Hospital in Kielce. All survivors were at least two years after cancer treatment termination. All patients were classified according to the risk of subfertility and infertility proposed by Wallace et al. [9]. Details concerning diagnosis, age at the time of therapy, the time since the end of therapy, and hormone levels are presented in Table 1, taking into consideration the risk groups proposed by Wallace et al. [9].

Total body irradiation was received by four survivors, 14 received irradiation to infradiaphragmatic areas, and 24 received cranial irradiation.

The control group included 24 males of similar age (18.69 \pm 2.29 years; median 18.5 years), healthy students and older patients from an outpatient clinic (in Bialystok), admitted for lymphadenopathy, pigmented nevus, or benign tumours (younger).

Blood was collected in the morning, and serum was separated and stored at $-80^{\circ}$ until study assay. All analyses were performed in the Department of Paediatric Laboratory Diagnostics of the Medical University of Bialystok. Follicular stimulating hormone (FSH), luteinising hormone (LH), and testosterone levels were assessed in all the studied patients using immunoenzymatic techniques (Siemens Diagnostic Product Corporation); inhibin B- by ELISA method with double-labelled antibodies against beta $B$ and alpha subunits. A set of antibodies produced by Oxford Bio-Innovation, UK was used for determinations.

The study was approved by the Local Ethical Committee. Written, informed consent was obtained from all the participants and/or their parents. 
TABLE 1. The risk group characteristics

\begin{tabular}{|c|c|c|c|c|c|c|}
\hline Diagnosis & N & & & $\begin{array}{l}\text { Age of diagnosis } \\
\text { (years) }\end{array}$ & $\begin{array}{l}\text { Age of follow-up } \\
\text { (years) }\end{array}$ & $\begin{array}{l}\text { Time from } \\
\text { diagnosis (years) }\end{array}$ \\
\hline ALL & 33 & \multirow[t]{6}{*}{ LR } & $N$ & 60 & 60 & 53 \\
\hline Wilms tumour & 12 & & $x$ & 7.41 & 17.86 & 11.12 \\
\hline \multirow{4}{*}{$\begin{array}{l}\text { Germ cell tumour (without } \\
\text { orchidectomy) }\end{array}$} & \multirow[t]{4}{*}{15} & & SD & 4.83 & 3.39 & 4.45 \\
\hline & & & Median & 5.25 & 17.50 & 11.00 \\
\hline & & & Min. & 0.50 & 12.00 & 2.00 \\
\hline & & & Max. & 17.00 & 25.00 & 23.50 \\
\hline \multirow[t]{2}{*}{ Non-Hodgkin lymphoma } & \multirow[t]{2}{*}{21} & \multirow[t]{6}{*}{ MR } & $N$ & 40 & 40 & 40 \\
\hline & & & $x$ & 10.04 & 16.53 & 6.49 \\
\hline STS (II-III stages) & 12 & & SD & 3.86 & 3.81 & 3.91 \\
\hline \multirow[t]{4}{*}{ Neuroblastoma } & \multirow[t]{3}{*}{7} & & Median & 10.00 & 16.00 & 5.25 \\
\hline & & & Min. & 1.50 & 11.00 & 0.50 \\
\hline & & & Max. & 16.50 & 25.00 & 15.00 \\
\hline & & \multirow[t]{6}{*}{ HR } & $N$ & 53 & 53 & 53 \\
\hline Hodgkin lymphoma & 31 & & $x$ & 11.23 & 17.98 & 6.79 \\
\hline STS IV stage & 10 & & SD & 4.45 & 3.08 & 4.90 \\
\hline \multirow{2}{*}{$\begin{array}{l}\text { SCT (stem cell transplantation) } \\
\text { (including total body irradiation) }\end{array}$} & \multirow{2}{*}{$\begin{array}{c}10 \\
4\end{array}$} & & Median & 12.50 & 17.00 & 5.50 \\
\hline & & & Min. & 1.50 & 11.40 & 0.50 \\
\hline \multirow[t]{7}{*}{ Supradiaphragmatic radiotherapy } & 14 & & Max. & 17.50 & 25.00 & 17.50 \\
\hline & & \multirow[t]{6}{*}{ Total } & $N$ & 153 & 153 & 146 \\
\hline & & & $x$ & 9.42 & 17.55 & 8.28 \\
\hline & & & SD & 4.74 & 3.44 & 4.95 \\
\hline & & & Median & 10.00 & 17.00 & 8.00 \\
\hline & & & Min. & 0.50 & 11.00 & 0.50 \\
\hline & & & Max. & 17.50 & 25.00 & 23.50 \\
\hline
\end{tabular}

\section{STATISTICS}

Statistical analysis was carried out using Statistica software. The mean values, standard deviations, median, minimum, and maximum were calculated. Student's t-test was used for normally distributed variables, whereas Mann-Whitney $U$-test was performed otherwise. Correlations between the features studied were defined using the Spearman's coefficient. Analyses were performed at $a$ $=0.05$ significance level.

\section{RESULTS}

All cancer survivors group (taken together), compared to the control group, presented lower mean inhibin B values ( $86.87 \pm 69.07 \mathrm{ng} / \mathrm{l}$ vs. $161.07 \pm 60.64 \mathrm{ng} / \mathrm{l}$; $p<0.001)$, and higher FSH $(10.23 \pm 13.35 \mathrm{mIU} / \mathrm{l}$ vs. 4.38 $\pm 2.39 \mathrm{mIU} / \mathrm{l} ; p<0.001)$ and $\mathrm{LH}(5.0 \pm 3.43 \mathrm{IU} / \mathrm{l}$ vs. 3.58 $\pm 2.17 \mathrm{IU} / \mathrm{l} ; p=0.016)$. Testosterone levels were comparable to the controls.
Considering the risk of gonadotoxicity, we observed elevated mean FSH levels in the three subgroups (LR group: $9.35 \pm 19.92 \mathrm{mIU} / \mathrm{l}$, MR group: $8.45 \pm 7.4 \mathrm{mIU} / \mathrm{l}$, HR group: $12.4 \pm 7.69 \mathrm{mIU} / \mathrm{l}$ vs. control group 4.38 $\pm 2.39 \mathrm{mIU} / \mathrm{l})$, the highest values were in the HR group $(p<0.05)$. Inhibin B values were comparable to the controls $(161.06 \pm 60.64 \mathrm{ng} / \mathrm{l})$ in the LR group (129.98 $\pm 77.08 \mathrm{ng} / \mathrm{l})$, and were lower in the MR (91.25 $\pm 48.58 \mathrm{ng} / \mathrm{l} ; p=0.003)$ and HR groups $(37.19 \pm 30.54 \mathrm{ng} / \mathrm{l}$; $p<0.001)$ with differences between the MR and HR group $(p=0.003)$ and between LR and HR group $(p<0.001)$. Mean serum LH values were normal in the LR group $(5.25 \pm 4.9 \mathrm{IU} / \mathrm{l})$ and HR group (4.36 $\pm 2.25 \mathrm{IU} / \mathrm{l})$, whereas they were elevated in the MR group $(5.55 \pm 2.14 \mathrm{IU} / \mathrm{l} ; p=0.002)$. However, no differences were noted between all study groups and controls in testosterone values. Testicular volumes were comparable in all risk groups and controls (Fig. 1A-E).

Abnormal levels of inhibin B $(<100 \mathrm{ng} / \mathrm{l} ;<1 \mathrm{SD}$ compared to the control group) were found in $53.7 \%$ of 

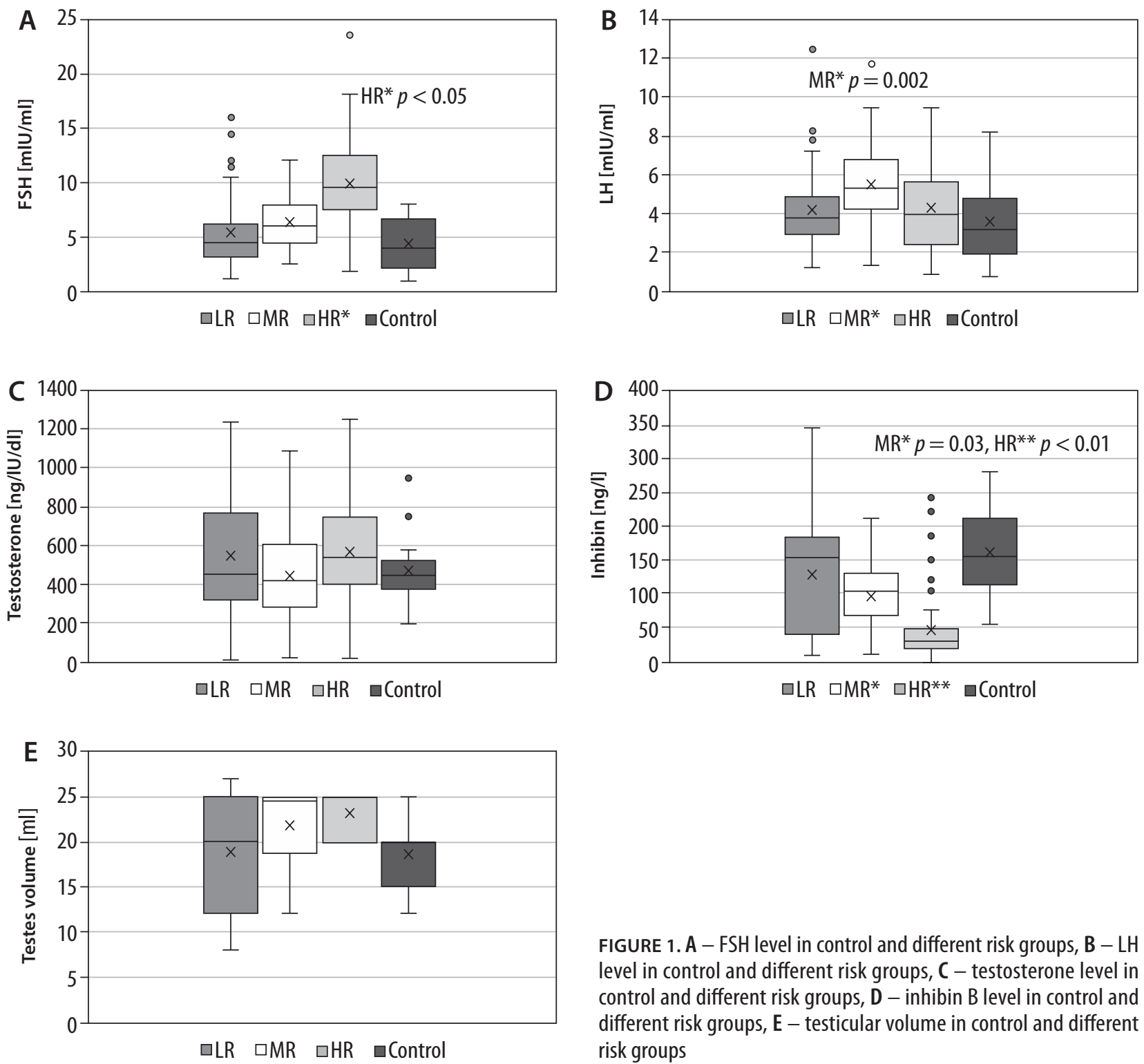

survivors. When we took into consideration the risk groups, lowered levels of inhibin B were observed in 15.2\% in the LR group, $47.6 \%$ in the MR group, and $94.1 \%$ in the HR group. Elevated FSH levels (> 1 SD) were observed in $54.3 \%$ of the survivors, including $20.4 \%$ in the LR group, $47.4 \%$ in the MR group, and $92.2 \%$ in the HR group.

The inhibin B : FSH ratio in the control group was $52.56 \pm 35.94$ in all cancer survivor groups: $20.39 \pm 27.47$ ( $p<0.001$ ), in the LR group: $41.7 \pm 36.57$ (NS), in the MR group: $16.42 \pm 11.39(p=0.002)$, and in the HR group 4.12 $\pm 4.8(p<0.001)$. The testosterone : $\mathrm{LH}$ ratio was 186.37 \pm 119.87 in controls and $143.55 \pm 152.74$ in all analysed group ( $p=0.03)$; the lowest in the MR group (83.40 \pm 52.28 , $p=0.001)$ and comparable to controls in the LR group $(145.08 \pm 90.01)$ and HR group (185.71 \pm 221.85$)$ (Table 2).

We found positive correlation between FSH and inhibin $\mathrm{B}$, but there was no influence of the age at diagnosis, age at follow-up, and length of the follow-up on hormonal values.

FIGURE 1. A - FSH level in control and different risk groups, B - LH level in control and different risk groups, $\mathbf{C}$ - testosterone level in control and different risk groups, $\mathbf{D}$ - inhibin $\mathrm{B}$ level in control and different risk groups, $\mathrm{E}$ - testicular volume in control and different risk groups

\section{DISCUSSION}

The current study was the first Polish multicentre analysis of male gonadal/hormonal function after anticancer treatment during childhood. The government monitoring program concerning the health status of childhood cancer survivors was created in 2008. Currently, more than 2000 children and adolescents participate in this program. In our first analysis, we found gonadal dysfunction as the most frequent endocrinopathy [12]. We have decided to perform more accurate analysis of the hormonal status in male cancer survivors using classification proposed by Wallace et al. [9], based on the type of disease and kind of treatment affecting the gonads. Due to the rarity of childhood cancers ( $<1 \%$ of all cancers) and differences in protocols, it is impossible to form large homogeneous groups of cancer survivors. In our opinion, this classification seems useful in the assessment of frequency of subfertility and degree of gonadotoxic treatment. 
Because we were not able to include sperm analyses in all survivors (a majority of males in our study did not accept this method), our study was based on the hormonal status. We assessed inhibin B, a product of Sertoli cells, as an indirect marker of spermatogenesis to be better than FSH evaluation. A large number of studies have presented the usefulness of inhibin B in the determination of Sertoli cell dysfunction and correlation between inhibin B levels and sperm concentration $[10,13]$. Previously, in a small group of cancer survivors, we found not only a lowered sperm count but also qualitative changes in spermatocytes [11]. Although recently Green et al. in a large cohort of cancer survivors did not confirm the utility of inhibin B and FSH in spermatogenesis assessment, other studies performed in large groups proved the usefulness of inhibin $\mathrm{B}$ and FSH in the determination of male reproductive status [14-16]. We found a negative correlation between inhibin $\mathrm{B}$ and $\mathrm{FSH}$ in males in all risk groups. In healthy males, this correlation appears at puberty and persists into adulthood [10]. Similar observations were made by Lahteenmaki et al., who found strong correlations between testicular size or FSH and inhibin B in postpubertal survivors [17].

In all study groups the mean levels of inhibin B were lower, whereas FSH was higher (except for the LR group) than in the control group. Similar results were obtained by Cicognani et al. and Wallace et al. [18, 19]. Not surprisingly, abnormal values were most frequent in the high-risk group, in which patients received the most vulnerable treatment, e.g. for Hodgkin lymphomas or soft tissue sarcomas, and underwent myeloablative chemotherapy or total body irradiation prior to bone marrow transplantation. The lowest inhibin B values $(<1 \mathrm{SD}$, $<100.0 \mathrm{ng} / \mathrm{l}$ ) were found in $94.1 \%$ of survivors from the HR group, while in the LR group abnormal inhibin B levels were presented only in $15.2 \%$ of survivors. The results obtained in our control group were lower than in studies performed by van Dorp et al. (reference values between 150 and $400 \mathrm{ng} / \mathrm{l}$ ) and van Casteren et al. (176.5 ng/l) $[20,21]$. However, the boys from our control and study groups were younger than in the studies mentioned above. Similarly, we observed the highest percentage of abnormal FSH values in the HR group (92.2\%) compared to the MR group (47.4\%) and LR group (20.4\%). In a study by Brignardello et al., symptoms of primary hypogonadism were found in $13.33 \%$ and abnormal sperm analysis in $42.2 \%$ of 310 adult childhood cancer survivors [22]. Tromp et al., in a large (565 survivors) cohort treated for all types of cancers, showed elevated FSH levels in $33 \%$ [15]. In an analysis by van Casteren et al. inhibin B was decreased in $67 \%$ of adults treated for cancer during childhood [21]. Laporte et al. received similar results of abnormal testicular function in $74 \%$ of survivors after haematopoietic cell transplantation [23]. This was confirmed by Anserini et al. in a group of 64 males after bone marrow transplantations $-70.3 \%$ presented azoospermia,
TABLE 2. The inhibin B : FSH ratio and the testosterone: LH ratio in control group and risk groups

\begin{tabular}{|c|c|c|c|}
\hline \multicolumn{2}{|c|}{ Risk group } & \multirow{2}{*}{$\begin{array}{c}\text { Testosterone/LH ratio } \\
24\end{array}$} & \multirow{2}{*}{\begin{tabular}{|c|} 
Inhibin/FSH ratio \\
24 \\
\end{tabular}} \\
\hline Control & $N$ & & \\
\hline & $x$ & 186.37 & 52.56 \\
\hline & $S D$ & 119.87 & 35.94 \\
\hline & Median & 160.22 & 46.30 \\
\hline \multirow{4}{*}{$\begin{array}{l}\text { LR } \\
\text { group }\end{array}$} & $N$ & 49 & 46 \\
\hline & $x$ & 145.08 & 41.70 \\
\hline & $S D$ & 90.01 & 36.57 \\
\hline & Median & 123.90 & 36.45 \\
\hline \multirow{4}{*}{$\begin{array}{l}\text { MR } \\
\text { group }\end{array}$} & $N$ & 37 & 38 \\
\hline & $x$ & 83.40 & 16.42 \\
\hline & $S D$ & 52.28 & 11.39 \\
\hline & Median & 77.21 & 15.35 \\
\hline \multirow{4}{*}{$\begin{array}{l}\text { HR } \\
\text { group }\end{array}$} & $N$ & 51 & 51 \\
\hline & $x$ & 185.71 & 4.12 \\
\hline & $S D$ & 221.85 & 4.80 \\
\hline & Median & 132.40 & 2.60 \\
\hline \multicolumn{2}{|c|}{ Control-LR } & ns & ns \\
\hline \multicolumn{2}{|c|}{ Control-MR } & 0.001 & 0.002 \\
\hline \multicolumn{2}{|c|}{ Control-HR } & ns & ns \\
\hline \multicolumn{2}{|c|}{ LR-HR } & ns & $p<0.001$ \\
\hline \multicolumn{2}{|l|}{ LR-MR } & 0.006 & ns \\
\hline \multicolumn{2}{|l|}{ MR-HR } & 0.001 & $p<0.001$ \\
\hline
\end{tabular}

especially after myeloablation with cyclophosphamide $-85.4 \%$ of survivors had azoospermia [24]. In our HR group, the most numerous were the survivors after HL treatment. Although the percentage of long-term survivors after HL is the highest, the late-effects are numerous. In Poland, protocols containing procarbazine were used until 2010. Patients with HL were treated with MOPP (mustargen, vincristine, procarbazine, prednisone) combined with B-DOPA (bleomycin, dacarbazine, vincristine, prednisone, doxorubicin), and in advanced clinical stages, additionally with infradiaphragmatic radiotherapy. Previously, we demonstrated that this kind of treatment had a damaging effect on gonadal function [11]. The use of six or more cycles of MOPP deteriorated spermatogenesis significantly. The most gonadotoxic was procarbazine. Currently, dacarbazine is used in HD treatment $[25,26]$. In a study conducted by Relander et al., the most visible gonadal dysfunctions were observed in HL survivors and after treatment with cyclophosphamide [27]. In German Trials based on the Hodgkin Study Group, abnormal FSH values were found in $93 \%$ of survivors treated with BEACOPP (bleomycin, etoposide, doxorubicin, cyclophosphamide, vincristine, procarbazine, prednisone) regimen 
[28]. Recently, Behringer et al., in a cohort containing 761 male adult HL survivors, found normal FSH and inhibin B values in nearly half of the patients treated with less intensive chemotherapy, whereas $88.8 \%$ of males after advanced-stage treatment presented the hormonal signs of azoospermia [29].

The inhibin B : FSH ratio was lowered in all groups of cancer survivors, being lowest in the HR group. Schmiegelow et al. found a decreased inhibin B : FSH ratio in males after treatment of brain tumours [30], similarly to Bordallo et al. [31], and Lahteenmaki et al. [16] who suggested the utility of this parameter in the estimation of spermatogenesis. Although in same exceptional cases they observed no correlation between inhibin B, FSH, and sperm counts.

Fertility was impaired in more than $60 \%$ of patients treated for solid tumours $[32,33]$. The protocols used for their treatment consisted most often of alkylating agents, such as cyclophosphamide, ifosfamide, or cisplatinum in higher cumulative doses, and radiotherapy directed to the abdominal/pelvic areas had the most deleterious impact on gonadal function $[7,34,35]$.

The function of steroidogenesis is less affected than spermatogenesis due to lower sensitivity of Leydig cells to radio- and chemotherapy. In all our study groups, $\mathrm{LH}$ levels were elevated and testosterone values were normal, indicating a compensated increase in LH due to insufficient testosterone production by Leydig cells. In the study made by van Casteren et al., elevated LH was found in $2 \%$ and testosterone in $10 \%$ of adult childhood cancer survivors [21]. Tromp et al. found decreased testosterone levels in $12 \%$ and increased $\mathrm{LH}$ in $3 \%$ of adult childhood cancer survivors [15]. Sieniawski et al. observed, in a group of HL survivors treated with BEACOPP regimen, abnormal testosterone in $57 \%$, $\mathrm{LH}$ in $21 \%$, and $\mathrm{FSH}$ in $93 \%$ of survivors [28]. Romerius et al. showed more deteriorated effect of anticancer treatment on Leydig cell function. They found a seven-fold increased odds ratio (OR) for hypogonadism (low testosterone values and/or elevated LH) in adult childhood-cancer survivors [36].

In the present study, we did not observe a protective role of younger age. In comparable risk groups, patients treated in younger age presented similar hormone values to those seen in survivors treated during puberty. This shows that prepubertal gonads present the same sensitivity to gonadotoxic treatment. This was confirmed by the observations of van Casteren et al., Ben Arush et al., Hobbie et al., and Soriano et al. [21, 26, 37, 38].

The hormonal status in the LR group was generally comparable to the controls, although $15.2 \%$ had lowered inhibin B level. The most representative were the boys treated for acute lymphoblastic leukaemia (33 patients). The treatment for acute lymphoblastic leukaemia (ALL) is not significantly deteriorating for gonads (cyclophosphamide doses are lower than in other protocols) but some patients - derived from the HR group - presented lower inhibin B values. In studies by Soriano et al. and van Casteren et al., normal testicular function was shown in ALL survivors $[21,38]$.

In conclusion, our study indicates increased risk of gonadal damage with a particularly high percentage observed in survivors from the HR group. Since the process of spermatogenesis is more affected than steroidogenesis, puberty and secondary sexual characteristics may be normal. Men having undergone more intensive chemotherapy present the hormonal symptoms of disturbed spermatogenesis and require follow-up in the future. They also should be informed about the impact of the treatment on gonadal function and possibilities of fertility preservation. The patients and parents should be informed about the possibility of lowered reproductive function, and pretreatment semen cryopreservation should be recommended.

\section{ACKNOWLEDGEMENT}

The study was supported by grant 153-79881L from the Medical University of Bialystok, Poland.

\section{DISCLOSURE}

The authors declare no conflict of interest.

\section{REFERENCES}

1. Bhatia S, Constine LS. Late morbidity after successful treatment of children with cancer. Cancer J 2009; 15: 174-180.

2. Marques P, Van Huellen H, Fitzpatrick A, et al. Late endocrine effects of cancer and cancer therapies in survivors of childhood malignancies. Minerva Endocrinol 2016; 41: 78-104.

3. Çağlar AA, Oğuz A, Pınarlı FG, et al. Thyroid abnormalities in survivors of childhood cancer. J Clin Res Pediatr Endocrinol 2014; 6: 144-51.

4. Brignardello E, Felicetti F, Castiglione A, et al. Gonadal status in long-term male survivors of childhood cancer. J Cancer Res Clin Oncol 2016; 142: 1127-1132.

5. Gunn HM, Rinne I, Emilsson H, et al. Primary gonadal insufficiency in male and female childhood cancer survivors in a long-term follow-up clinic. J Adolesc Young Adult Oncol 2016; 5: 344-350.

6. Kenney LB, Cohen LE, Shnorhavorian ML, et al. Male reproductive health after childhood, adolescent, and young adult cancers: a report from the children's oncology group. J Clin Oncol 2012; 30: 3408-3416.

7. Nandagopal R, Laverdiere C, Mulrooney D, et al. Endocrine late effects of childhood cancer therapy: a report from the children's oncology group. Hormone Res 2008; 69: 65-74.

8. Green DM, Liu W, Kutteh WH, et al. Cumulative alkylating agent exposure and semen parameters in adult survivors of childhood cancer: a report from the St Jude Lifetime Cohort Study. Lancet Oncol 2014; 15: 1215-1223.

9. Wallace WH, Anderson RA, Irvine DS. Fertility preservation for young patients with cancer: who is at risk and what can be offered? Lancet Oncol 2005; 6: 209-218.

10. Crofton PM, Thomson AB, Evans AEM, et al. Is inhibin B a potential marker of gonadotoxicity in prepubertal children treated for cancer? Clin Endocrinol 2003; 58: 296-301. 
11. Krawczuk-Rybak M, Solarz E, Wojtkowska M, et al. Gonadal function in young men after the treatment for Hodgkin lymphoma. Pediatr Endocrinol Diabetes Metab 2009; 15: 85-92.

12. Krawczuk-Rybak M, Panasiuk A, Muszynska-Rosłan K, et al. Health status of Polish children and adolescents after ending of anticancer treatment. Polish Oncol 2012; 15: 96-102.

13. Chada M, Prusa R, Bronsky J, et al. Inhibin B, follicle stimulating hormone, luteinizing hormone and testosterone during childhood and puberty in males: changes in serum concentrations in relations to age and stage of puberty. Physiol Res 2003; 52: 45-51.

14. Green DM, Zhu L, Zhang N, et al. Lack of specificity of plasma concentrations of inhibin B and follicle stimulating hormone for indentification of azoospermic survivors of childhood cancer: a report from the St Jude lifetime cohort study. J Clin Oncol 2013; 31: 1324-1328.

15. Tromp K, Claessens JJ, Knijnenburg SL, et al. Reproductive status in adult male long-term survivors of childhood cancer. Hum Reprod 2011; 26: 1775-1783.

16. Lahteenmaki PM, Arola M, Suominen J, et al. Male reproductive health after childhood cancer. Acta Paediatr 2008; 97: 935-942.

17. Lahteenmaki PM, Toppari J, Ruokonen A, et al. Low serum inhibin $B$ concentrations in male survivors of childhood malignancy. Eur J Cancer 1999; 35: 612-619.

18. Cicognani A, Cacciari E, Pasini A, et al. Low serum inhibin B levels as a marker of testicular damage after treatment for a childhood malignancy. Eur J Pediatr 2000; 159: 103-107.

19. Wallace EM, Groome NP, Riley SC, et al. Effects of chemotherapy-induced testicular damage on inhibin, gonadotropin, and testosterone secretion: a prospective longitudinal study. J Clin Endocrinol Metab 1997; 82: 3111-3115.

20. van Dorp W, van der Geest IM, Laven JS, et al. Gonadal function recovery in very long-term male survivors of childhood cancer. Eur J Cancer 2013; 49: 1280-1286.

21. van Casteren NJ, van der Linden GH, Hakvoort-Cammel FG, et al. Effect of childhood cancer treatment on fertility markers in adult male long-term survivors. Pediatr Blood Cancer 2009; 52: 108-112.

22. Brignardello E, Felicetti F, Castiglione A, et al. Endocrine health conditions in adult survivors of childhood cancer: the need for specialized adult-focused follow-up clinics. Eur J Endocrinol 2013; 168: 465-472.

23. Laporte S, Couto-Silva AC, Trabado S, et al. Inhibin B and anti-Mullerian hormone as markers of gonadal function after hematopoietic cell transplantation during childhood. BMC Pediatrics 2011; 11: 20.

24. Anserini P, Chiodi S, Spinelli S, et al. Gonadal function post transplantation. Semen analysis following allogeneic bone marrow transplantation. Additional data for evidence-based counselling. Bone Marrow Transplant 2002; 3: 447-451.

25. van Dorp W, van Beek RD, Laven JS, et al. Long-term endocrine side effects of childhood Hodgkin's lymphoma treatment: a review. Hum Reprod 2012; 18: 12-28.

26. Ben Arush MW, Solt I, Lightman A, et al. Male gonadal function in survivors of childhood Hodgkin and non-Hodgkin lymphoma. Ped Hematol Oncol 2000; 17: 239-245.

27. Relander T, Cavallin-Stahl E, Garwicz S, et al. Gonadal and sexual function in men treated for childhood cancer. Med Ped Oncol 2000; 35: 52-63.

28. Sieniawski M, Reineke T, Nogova L, et al. Fertility in male patients with advanced Hodgkin lymphoma treated with BEACOPP: a report of the German Hodgkin Study Group (GHSG). Blood 2008; 111: 71-76

29. Behringer K, Mueller H, Goergen $\mathrm{H}$, et al. Gonadal function and fertility in survivors after Hodgkin lymphoma treatment within the German Hodgkin Study Group HD13 to HD15 trials. J Clin Oncol 2013 10; 31: 231-239.
30. Schmiegelow M, Lassen S, Poulsen HS, et al. Gonadal status in male survivors following childhood brain tumors. J Clin Endocrin Metabol 2001; 86: 2446-2452.

31. Bordallo MA, Guimarães MM, Pessoa $\mathrm{CH}$, et al. Decreased serum inhibin B/FSH ratio as a marker of Sertoli cell function in male survivors after chemotherapy in childhood and adolescence. J Ped Endocrin Metabol 2004; 17: 879-887.

32. Aubier F, Flamant F, Brauner R, et al. Male gonadal function after chemotherapy for solid tumors in childhood. J Clin Oncol 1989; 7: 304-309.

33. Meistrich ML, Wilson G, Brown BW, et al. Impact of cyclophosphamide on long-term reduction in sperm count in men treated with combination chemotherapy for Ewing and soft tissue sarcomas. Cancer 1992; 70: 2703-2712.

34. Muller J. Impact of cancer therapy on the reproductive axis. Horm Res 2003; 59 (suppl 1): 12-20.

35. Servitzoglou M, De Vathaire F, Oberlin O, et al. Dose-Effect Relationship of Alkylating Agents on Testicular Function in Male Survivors of Childhood Lymphoma. Pediatr Hematol Oncol 2015; 32: 613-623.

36. Romerius P, Ståhl O, Moëll C, et al. Hypogonadism risk in men treated for childhood cancer. J Clin Endocrinol Metab 2009; 94 : 4180-4186.

37. Hobbie WL, Ginsberg JP, Ogle SK, et al. Fertility in males treated for Hodgkin's disease with COPP/ABV hybrid. Pediatr Blood Cancer 2005; 44: 193-196.

38. Soriano-Guillen L, Munoz-Calvo MT, Pozo-Roman J, et al. Changes in gonadal function in post-pubertal male survivors of acute lymphoblastic leukemia and Hodgkin's disease. An Esp Pediatr 2000; 53: 318-323. 